\title{
Using highly variable warfarin dosing to identify patients at risk for adverse events
}

Lyndonna Marrast ${ }^{1}$, Mary Evans ${ }^{1}$, Al Ozonoff $^{2}$, Lori E Henault ${ }^{1}$ and Adam J Rose ${ }^{3,1^{*}}$

\begin{abstract}
Background: Patients who receive highly variable doses of warfarin may be at risk for poor anticoagulation control and adverse events. However, we lack a system to identify patients with the highest dose variability. Our objectives were to develop a scoring system to identify patients with high dose variability, and to validate this new measure by demonstrating that patients so identified have poor anticoagulation control and higher rates of adverse events (criterion validity).

Methods: We used a database of over 4, 000 patients who received oral anticoagulation in community practice between 2000-2002. We reviewed the charts of 168 patients with large warfarin dose variation and agreed on 18 risk factor definitions for high dose variability. We identified 109 patients with the highest dose variability (cases), as measured by coefficient of variation (CoV, SD/mean). We matched each case to two controls with low dose variability. Then, we examined all 327 charts, blinded to case/control status, to identify the presence or absence of the 18 risk factors for dose variability. We performed a multivariable analysis to identify independent predictors of high CoV. We also compared anticoagulation control, as measured by percent time in therapeutic range (TTR), and rates of adverse events between groups.

Results: CoV corresponded with other measures of anticoagulation control. TTR was 53\% among cases and 79\% among controls $(p<0.001)$. CoV also predicted adverse events. Six cases experienced a major hemorrhage versus 1 control $(p<0.001)$ and 3 cases had a thromboembolic event versus 0 control patients $(p=0.04)$. Independent predictors of high dose variability included hospitalization $(O R=21.3)$, decreased oral intake $(O R=12.2)$, use of systemic steroids $(O R=6.1)$, acetaminophen $(O R=4.0)$ and antibiotics $(O R=2.7 ; p<0.05$ for all).

Conclusion: CoV can be used to identify patients at risk for poor anticoagulation control and adverse events. This new measure has the potential to identify patients at high risk before they suffer adverse events.
\end{abstract}

Keywords: anticoagulants, dose variability, medication therapy management, risk factors, warfarin.

\section{Background}

Warfarin is the standard anticoagulation treatment for atrial fibrillation, venous thromboembolism (VTE), and mechanical heart valves [1-4]. Close monitoring of the International Normalized Ratio (INR) is required due to the drug's very narrow therapeutic window. Many factors can affect INR levels $[1,5,6]$. Values must be kept within range to reduce the risk of hemorrhage $[7,8]$ and the risk of developing thromboembolism [9]. Previous studies

\footnotetext{
* Correspondence: adamrose@bu.edu

${ }^{3}$ Center for Health Quality, Outcomes, and Economic Research, Bedford VA Medical Center, Bedford, MA, USA

Full list of author information is available at the end of the article
}

have shown that patients experiencing better anticoagulation control have fewer such adverse events [10-14].

Assessment of adequate anticoagulation control has traditionally been determined by examining INR values themselves, through summary statistics such as percent time in therapeutic range (TTR) [15] or INR variability $[16,17]$. Several studies have explored the patient-level predictors of control as measured by TTR $[10,18,19]$. However, there is reason to believe that variability in warfarin doses could also serve to identify patients who are experiencing poorly controlled anticoagulation, thus placing them at risk for adverse events.

We therefore used a large, nationally representative database of community-based oral anticoagulation care
C Biomed Central

() 2011 Marrast et al; licensee BioMed Central Ltd. This is an Open Access article distributed under the terms of the Creative Commons Attribution License (http://creativecommons.org/licenses/by/2.0), which permits unrestricted use, distribution, and reproduction in any medium, provided the original work is properly cited. 
to address three related questions. First, we sought to develop a measure of warfarin dose variability that could be used to describe a population and identify patients with highly variable doses over time. Second, we sought to internally validate this new dose variability score as a measure of anticoagulation control using criterion validity. That is, we sought to demonstrate that patients identified as having high dose variability have worse anticoagulation control as measured by TTR and are at higher risk for adverse events than patients with less variability. Finally, through chart review, we sought to identify patient-level predictors of high dose variability. Our overarching goal was to develop a score that could be used to identify patients at high risk for complications.

\section{Methods}

\section{Database}

The Anticoagulation Consortium to Improve Outcomes Nationally (ACTION) study was a large prospective cohort study designed to assess the management of warfarin in community practice within the US [19-21]. A total of 101 participating sites in 31 states recruited 6761 patients receiving long-term oral anticoagulation. All sites used a freely-available software package called CoumaCare for tasks such as patient tracking and recording clinical data. In the database, clinicians updated patient's weekly warfarin dose at each visit. Because the present study relied upon chart reviews, we limited this study to the 47 sites of care that recorded complete notes for at least $90 \%$ of INR values. Excluded sites recorded notes only when the INR was not therapeutic. Therefore, this study was limited to 4489 patients.

Enrollment in ACTION occurred between April 2000 and February 2002. Patients were eligible to participate if they were 18 years or older and able to provide informed consent. All data were collected and their completeness rigorously ensured by McKesson HBOC, an independent data management organization. Missing data fields and data entry errors were resolved directly with the sites by the data coordinating center on a weekly basis before the data were transmitted to study investigators. The study protocol was approved by the Western Institutional Review Board of Olympia, WA, and by local review boards where they existed.

Patients were eligible for inclusion in the present study if they had an INR target range of 2-3. Indications for anticoagulation were grouped as follows: atrial fibrillation, venous thromboembolism, valvular heart disease/prosthetic heart valve, and all others. The database included demographics (age, gender, and race) and several comorbid conditions (coronary artery disease, congestive heart failure, hypertension, diabetes) as recorded by the patients' clinicians. Weekly dose of warfarin was recorded for all patients in the database, and was updated by clinicians at each visit. We used these weekly doses to assess the stability of warfarin dose over time for each patient, as will be explained below.

\section{Chart Reviews}

We performed two separate chart reviews, in our efforts to create a score that describes patients with high warfarin dose variability. The first review was implicit; it was performed by chart reviewers without relying upon pre-established definitions. Three physician examiners (LM, ME, and AJR) independently reviewed the charts of 168 patients who had a 2-fold or greater difference between the lowest and highest weekly warfarin dose (e.g. $14 \mathrm{mg} /$ week versus $28 \mathrm{mg} /$ week). The concept behind the review was to remain open to the possibilities of factors that may be present in the database rather than rely solely upon preconceived ideas. Next, the reviewers met and compiled a list of 18 variables believed to have played the greatest role in the dose variability. They reached a consensus regarding a standard definition for each variable in the chart review instrument (Table 1).

We found that the criterion used to identify patients with high dose variability (i.e. twofold or greater dose range) did not capture the dose variability we had in mind. Specifically, the method identified a relatively large proportion of patients with one or two outlier doses but otherwise stable dosing. Not all of the patients identified by this score seemed to be experiencing the highly variable anticoagulation control that we were trying to capture. We therefore decided to use the coefficient of variation (CoV) to characterize warfarin dose variability. $\mathrm{CoV}$ is defined as the standard deviation of the weekly warfarin dose divided by the mean weekly warfarin dose.

We labeled all patients with $\mathrm{CoV}$ greater than 0.2 as patients with high dose variation ("cases"). There were 123 such patients, representing $2.7 \%$ of the dataset. Patients with CoV below 0.05 (1019 patients, representing $23 \%$ of the dataset) were eligible to be controls. Each case was matched to 2 controls within the same site of care. Charts were excluded if: 1) there were no controls available to match the case patients or 2) the patient was new to warfarin (less than 1 month experience as of study entry). A total of 14 cases and 12 potential controls were removed for these reasons, leaving 109 cases and 218 controls.

The reviewers then independently reviewed charts to identify the 18 variables defined in the chart review instrument. This second review was explicit in that it relied upon the variable definitions described in the instrument. During this second chart review, reviewers were blinded to whether the patient was a case or a control patient. If a factor was present at any time, we recorded this indicator as "1" (present) versus "0" (not present). Each reviewer abstracted one-third of the charts. Fifty of the charts were 
Table 1 Chart Review Instrument

\begin{tabular}{|c|c|c|}
\hline & Variable & Definition \\
\hline 1 & Diet & $\begin{array}{l}\text { Any mention of "greens", specific foods high in vitamin } \mathrm{K} \text {, and dietary content of vitamin K. DOES NOT } \\
\text { INCLUDE statements that the vitamin K content of the diet is unchanged. }\end{array}$ \\
\hline 2 & Dietary Supplements & $\begin{array}{l}\text { Any mention of multivitamins, Ensure, Boost, Slimfast, etc. as they relate to vitamin K intake. DOES NOT } \\
\text { INCLUDE simply listing a multivitamin in the medication list. }\end{array}$ \\
\hline 3 & Adherence & $\begin{array}{l}\text { Any mention of problems with adherence to pill-taking, including unauthorized self-adjustment of doses and } \\
\text { memory issues. DOES NOT INCLUDE dose confusion after a hospital stay and DOES NOT INCLUDE aspects of } \\
\text { adherence (diet, lab follow up, etc.) beyond pill-taking. }\end{array}$ \\
\hline 4 & Hospital or Nursing Home Stay & $\begin{array}{l}\text { Any mention of a hospital or nursing home stay EXCEPT for CHF (because that has its own variable - see } \\
\text { below) }\end{array}$ \\
\hline 5 & Nausea and Vomiting & Any mention \\
\hline 6 & $\begin{array}{l}\text { Decreased PO Intake or } \\
\text { Decreased Appetite }\end{array}$ & Any mention \\
\hline 7 & Diarrhea & Any mention \\
\hline 8 & Decompensated CHF & $\begin{array}{l}\text { Any mention of fluid overload, fluid retention, edema, pulmonary edema. Any titration of lasix doses, trending } \\
\text { of weight regarding fluid status, use of metolazone (i.e. zaroxolyn), or any obvious CHF regimen. Any hospital } \\
\text { admissions for fluid overload. }\end{array}$ \\
\hline 9 & Alcohol & Any mention of alcohol except "denies." Exception - one serving per day or less does not count \\
\hline 10 & Amiodarone & Any mention of amiodarone or its brand names "pacerone" or "cordarone." \\
\hline 11 & Acetaminophen & Any mention of acetaminophen, products containing acetaminophen. Includes the abbreviation "APAP." \\
\hline 12 & NSAIDS/COX-2 Inhibitors & Any mention at all, including mention in the medication list. \\
\hline 13 & Procedures & $\begin{array}{l}\text { Any mention of a procedure in conjunction with a dose reduction or a "hold" of warfarin - even if the } \\
\text { procedure is ultimately cancelled. }\end{array}$ \\
\hline 14 & Cancer & $\begin{array}{l}\text { Any mention of cancer, with or without specific therapies such as chemotherapy, radiation, etc. DOES NOT } \\
\text { INCLUDE a mere history of cancer. }\end{array}$ \\
\hline 15 & Missed Appointments & Any recorded missed appointments - unless due to hospitalization (which is a different variable). \\
\hline 16 & Systemic Corticosteroids & Any mention. DOES NOT INCLUDE joint injections, skin creams, etc. \\
\hline 17 & Alternative Medications & Any mention - including but not limited to saw palmetto, St. John's Wort, Echinacea, Coenzyme Q10, etc. \\
\hline 18 & Antibacterial Antibiotics & Any mention - must be systemic therapy, not local (such as skin creams, etc.) \\
\hline
\end{tabular}

For all items, one mention is sufficient to mark the item "yes." Mark a " 1 " if present, or a "0" if absent.

reviewed by all three reviewers to assess inter-rater agreement.

\section{Adverse Events}

Ischemic stroke/systemic arterial embolism, VTE and major hemorrhage were the adverse outcomes of interest. We defined major hemorrhage according to the definition of the International Society of Thrombosis and Haemostasis: a fatal event, an event requiring hospitalization with transfusion of at least two units of packed red blood cells, or bleeding involving a critical anatomical site such as the cranium or the retroperitoneum [22]. All patient progress notes were individually reviewed for evidence of adverse events; events were validated directly with the sites by McKesson.

\section{Statistical Analyses}

Kappa $(\kappa)$ statistics were computed to assess inter-rater reliability for the second chart review. To assess significance of effects when comparing categorical variables with the matched design, we used Monte Carlo permutation methods with 10, 000 iterations to compute empirical pvalues. Case-control status within each "cluster" of matched observations was randomly permuted 10, 000 times, with a test statistic (e.g., Pearson's chi-square statistic) calculated upon each iteration. This was used as a reference distribution, under the null hypothesis of no association with case status, to compute the empirical p-value. Groups were compared on continuous variables using a generalized linear model to account for correlation between each case and its matched controls. We used conditional logistic regression models to determine the factors that independently predict case status while controlling for patient level covariates (i.e. age, gender, race, co-morbid conditions). Analyses were performed using SAS, version 9.1 (SAS Corporation) and R, version 2.8 (R Foundation).

\section{Results}

\section{Baseline Characteristics}

There were 109 cases with high dose variability and 218 site-matched controls with low dose variability (Table 2). The mean coefficient of variation $(\mathrm{CoV})$ of the cases was 0.24 and the mean for the controls was $0.02(\mathrm{p}<0.001)$. The two groups were similar in demographics: most participants were white (89\% of cases and $94 \%$ of controls) and many were 75 years of age or older ( $50 \%$ of cases and $42 \%$ of controls). Forty-five percent of cases were female, compared to $32 \%$ of controls $(\mathrm{p}=0.02)$. Atrial fibrillation 
Table 2 Baseline patient characteristics compared between cases $(n=109)$ and controls $(n=218)$

\begin{tabular}{lccc}
\hline Demographics & Cases (\%) & Controls (\%) & P-value \\
\hline Age 75 or Older & 50 & 42 & $0.20^{*}$ \\
Female & 45 & 32 & $0.02^{*}$ \\
Nonwhite Race & 11 & 6 & $0.10^{*}$ \\
Hypertension & 48 & 47 & $0.99^{*}$ \\
Diabetes & 21 & 21 & $0.99^{*}$ \\
Coronary Artery Disease & 39 & 34 & $0.53^{*}$ \\
Follow up time & 10.9 months & 11.5 months & $<0.001 \dagger$ \\
\# INR/month & 2.3 & 1.2 & $<0.001 \dagger$ \\
Indication: & & & $0.26^{*}$ \\
Atrial Fibrillation & 67 & 58 & \\
VTE & 11 & 13 & \\
Valvular Heart disease & 6 & 5 & \\
Other & 16 & 24 & \\
\hline
\end{tabular}

*Comparison via Monte Carlo simulation

†Comparison via Generalized Estimating Equations (GEE)

was the indication for anticoagulation in $67 \%$ and $58 \%$ of the cases and controls, respectively. Among the 69 patients with "other" indications for anticoagulation, 27 were anticoagulated for stroke, transient ischemic attack, or cerebrovascular disease; 22 were anticoagulated for congestive heart failure; 13 were anticoagulated for coronary artery disease; 4 were anticoagulated for hypercoagulability; and 3 were anticoagulated for other reasons. Co-morbidities such as hypertension, diabetes, and coronary artery disease were similar between groups.

Validation of Coefficient of Variation as a Measure of Risk $\mathrm{CoV}$ corresponded well with other measures of anticoagulation control and risk for adverse events. The 109 case patients had a mean TTR of 53\%, compared to $79 \%$ for the 218 control patients $(\mathrm{p}<0.001)$. Cases had a higher rate of adverse events. Six case patients experienced major hemorrhage, compared to only 1 control patient $(\mathrm{p}<0.001)$. Three case patients had thromboembolic events ( 2 embolic strokes and 1 pulmonary embolism), compared to 0 control patients $(\mathrm{p}=0.04)$.

\section{Predictors of Dose Variability}

We assessed predictors of dose variability using chart review. The 3 reviewers achieved a very good rate of inter-rater reliability (three-way $\kappa=0.76$ ). In the unadjusted analysis (Table 3), most of the risk factors we examined were associated with case status. Particularly strong associations were seen with amiodarone (12 cases vs. no controls, $\mathrm{p}<0.001)$ and a diagnosis of cancer (8 cases vs. 1 control, $\mathrm{p}<0.001)$. When present, these variables were highly indicative of high $\mathrm{CoV}$.

After adjustment for covariates (Table 4), variables independently associated with large dose variation included hospital/nursing home stay ( OR = 21.3),
Table 3 Proportion of cases and controls with risk factors for extreme dose variability (unadjusted results).

\begin{tabular}{|c|c|c|c|}
\hline Risk Factors & $\begin{array}{c}\text { Cases } \\
(\mathrm{n}=109)\end{array}$ & $\begin{array}{l}\text { Controls } \\
(n=218)\end{array}$ & p-value* \\
\hline Acetaminophen & $33(30 \%)$ & $30(14 \%)$ & $<0.001$ \\
\hline Adherence & $48(44 \%)$ & $67(31 \%)$ & 0.01 \\
\hline Alcohol & $9(8 \%)$ & $16(7 \%)$ & 0.99 \\
\hline Alternative Medication & $11(10 \%)$ & $10(5 \%)$ & 0.08 \\
\hline Amiodarone & $12(11 \%)$ & $0(0 \%)$ & $<0.001$ \\
\hline Antibiotic Use & $47(43 \%)$ & $44(20 \%)$ & $<0.001$ \\
\hline Cancer & $8(7 \%)$ & $1(0 \%)$ & $<0.001$ \\
\hline CHF (Decompensated) & $14(13 \%)$ & $7(3 \%)$ & 0.001 \\
\hline Decreased Oral Intake & $21(19 \%)$ & $8(4 \%)$ & $<0.001$ \\
\hline Diarrhea & $15(14 \%)$ & $10(5 \%)$ & 0.003 \\
\hline Dietary Supplement & $8(7 \%)$ & $6(3 \%)$ & 0.06 \\
\hline Dietary Vitamin $\mathrm{K}$ & $40(37 \%)$ & $73(34 \%)$ & 0.61 \\
\hline Hospitalizations/Nursing Home & $47(43 \%)$ & $12(6 \%)$ & $<0.001$ \\
\hline Missed Appointments & $12(11 \%)$ & $22(10 \%)$ & 0.99 \\
\hline Nausea/Vomiting & $10(9 \%)$ & $5(2 \%)$ & 0.01 \\
\hline NSAID Use & 19 (17\%) & $18(8 \%)$ & 0.02 \\
\hline Procedures & $28(26 \%)$ & 41 (19\%) & 0.21 \\
\hline Systemic Steroids & 12 (11\%) & $9(4 \%)$ & 0.03 \\
\hline
\end{tabular}

All variables were obtained by chart review and all are yes/no variables. Boldface variables are significant at the 0.05 level.

*Via Monte Carlo simulation

decreased oral intake $(\mathrm{OR}=12.2)$, use of systemic steroids $(\mathrm{OR}=6.1)$, use of acetaminophen $(\mathrm{OR}=4.0)$, and use of antibiotics $(\mathrm{OR}=2.7)$. Effect size of amiodarone and cancer could not be calculated because there were too few controls with these variables. The presence of these variables precluded model convergence; therefore, these variables were omitted from the model.

\section{Discussion}

In this study, we have describe a new measure to identify patients at risk for adverse outcomes of anticoagulation care, have shown that the measure is correlated with INR control and adverse events, and have examined patientlevel predictors of being in this high-risk group. The characteristics independently predictive of large weekly variation in warfarin dose were hospitalization/nursing home stay, decreased oral intake, use of systemic steroids, acetaminophen, and antibiotics. In addition, the use of amiodarone and a diagnosis of cancer were almost certainly risk factors for high $\mathrm{CoV}$, though we could not estimate an effect size.

This study suggests that CoV could be an important tool for identifying patients at high risk for poorly controlled anticoagulation therapy and adverse events. Patients identified as high-risk might be referred for case management, adherence training, more intensive followup, or indeed reconsideration of whether this particular patient is a good candidate for warfarin. The utility of 
Table 4 Multivariate analysis of risk factors for extreme warfarin variability

\begin{tabular}{lcc}
\hline Chart Review Variables & Odds Ratio $(\mathbf{9 5 \%} \mathrm{Cl})$ & p-value \\
\hline Acetaminophen & $\mathbf{4 . 0}(\mathbf{1 . 3 3}$ to 6.30$)$ & $\mathbf{0 . 0 1}$ \\
Adherence & $2.0(0.87$ to 4.65$)$ & 0.10 \\
Alcohol & $2.5(0.65$ to 10.00$)$ & 0.18 \\
Alternative Medication & $2.0(0.38$ to 9.63$)$ & 0.44 \\
Amiodarone & $*$ & $*$ \\
Antibiotic Use & $\mathbf{2 . 7}(\mathbf{1 . 1 1}$ to 6.33$)$ & $\mathbf{0 . 0 3}$ \\
Cancer & $*$ & $*$ \\
CHF (Decompensated) & $2.0(0.34$ to 11.58$)$ & 0.44 \\
Decreased Oral Intake & $\mathbf{1 2 . 2}(\mathbf{2 . 2 5}$ to 65.68$)$ & $\mathbf{0 . 0 0 4}$ \\
Diarrhea & $2.8(0.51$ to 15.67$)$ & 0.23 \\
Dietary Supplement & $1.0(0.12$ to 7.90$)$ & 0.98 \\
Dietary Vitamin K & $2.1(0.86$ to 4.92$)$ & 0.10 \\
Hospitalizations/Nursing Home & $\mathbf{2 1 . 3}(\mathbf{6 . 2 1}$ to 73.14$)$ & $<\mathbf{0 . 0 0 1}$ \\
Missed Appointments & $1.6(0.51$ to 5.15$)$ & 0.42 \\
Nausea/Nomiting & $4.4(0.70$ to 27.91$)$ & 0.11 \\
NSAID Use & $1.3(0.36$ to 4.72$)$ & 0.69 \\
Procedures & $1.4(0.59$ to 3.36$)$ & 0.44 \\
Systemic Steroids & $\mathbf{6 . 1}(\mathbf{1 . 1 0}$ to 34.20$)$ & $\mathbf{0 . 0 4}$ \\
\hline
\end{tabular}

Variables are adjusted for all other variables in the table, as well as for age, gender, race, and comorbid conditions (not shown).

* These variables were not estimable in the multivariate model, because too few control patients had these characteristics. Therefore, these variables were omitted from the model.

such an approach for preventing adverse events could be examined in a prospective study. Anticoagulation control (as measured by TTR) could also be used to prospectively identify patients at high risk for adverse events. Our study did not directly compare the ability of these two measures (TTR vs. dose CoV) to identify patients at highest risk for adverse events; this would also be a suitable topic for future study. We suspect that, in many care settings, there is no effort to prospectively identify patients at high risk of adverse events. If the utility of this approach can be established, it may be more widely employed.

An ideal next step to further this research would be to use $\mathrm{CoV}$ to identify patients at high risk for poor outcomes in the context of a quasi-experimental design. At some sites of care, patients with extremely high $\mathrm{CoV}$ might be referred for case management, adherence training, more intensive follow-up, or indeed reconsideration of whether this particular patient is a good candidate for warfarin. At other sites of care, $\mathrm{CoV}$ would be noted, but not acted upon. The outcomes for patients with high $\mathrm{CoV}$ (TTR and hopefully clinical outcomes) would be compared, and the effectiveness and cost-effectiveness of the intervention assessed.

Hospitalization had the strongest association with unstable anticoagulation control of any variable in our multivariate analysis. Being hospitalized can contribute to variable dosing for several reasons. When patients are hospitalized, warfarin therapy is often interrupted, and patients may receive parenteral anticoagulation or no anticoagulation at all. Hospitalization also involves large changes in the patient's lifestyle and diet. Returning home, the patient attempts to re-establish usual habits while often restarting warfarin therapy at the previous dose. Unsurprisingly, this combination of circumstances produces out-of-range INR values. Hospitalization is also a general marker of illness severity, which can predict poorer anticoagulation control both before and after hospitalization. Previous studies have also examined the event of a hospitalization as a time-dependent inducer of variable anticoagulation control [23].

Several studies have shown an association with warfarin and acetaminophen [24,25]. Hylek et al. [26] described acetaminophen as an underrecognized source of INR elevation. Her study which included a case-control prospective design assessed patients with high INR values $(>6.0)$. Acetaminophen was noted as a risk factor that was documented only as case studies in the literature previously. One study examined the prevalence of adverse warfarindrug combinations in a post-mortem toxicology database. Acetaminophen accounted for more than half of the warfarin drug interactions. In that study, there were more deaths with the combination of acetaminophen and warfarin than with either drug alone [27]. Despite these data, discordant findings showing lack of an association with acetaminophen and warfarin potentiation have been reported [28-30]. The present study reinforces the theory that the use of acetaminophen can contribute to poor anticoagulation control.

Several other studies have described factors associated with anticoagulation control [31-33]. One study, similar to ours, examined factors that contribute to unstable control and found no association with dietary habits or the presence of comorbid conditions. Instead, they found greater instability among patients working full-time, among those with inadequate understanding of oral anticoagulation therapy, and among those with CYP2C9*3 variants [31]. Other studies have examined factors associated with extremely stable control. Witt et al. $[32,33]$ performed 2 studies looking at patients that spent $100 \%$ of the time in therapeutic range. Both studies found that older age, lack of co-morbidities and a standard INR target range (i.e. 2-3) were associated with stable control.

There are several strengths to our study. We used a large, nationally representative database of patients receiving warfarin in community-based practice. Our three chart reviewers achieved a very good rate of interrater reliability. Finally, this database (ACTION) contains weekly warfarin doses for all patients. These data are usually not available, since warfarin is often prescribed 
"use as directed" and so dose changes cannot be reliably abstracted. This is a unique feature of this database, without which we could not have performed this study.

Despite this our study has some limitations. First, this study did not address the question of whether high dose variability is a cause or a consequence of poor anticoagulation control, although we would suspect that it is predominantly a consequence of it. Nevertheless, this study does demonstrate that dose variability is both measurable and related to important clinical outcomes, regardless of its causal relationship with anticoagulation control. As such, it might be used to identify patients at elevated risk for adverse events. Second, this study was limited to risk factors for high $\mathrm{CoV}$ that were clearly documented in the clinical notes; however, some risk factors may have been present, but poorly recognized or poorly documented. Our results with regard to risk factors for high CoV should be regarded as exploratory, particularly where a risk factor was shown not to predict high $\mathrm{CoV}$, because an absence of documentation is not conclusive proof that something did not occur. Third, we emphasize that we have only subjected our new scoring system to internal validation, i.e. within the same dataset. A higher level of validation would be attained by demonstrating its utility in a separate dataset. Fourth, the confidence intervals identified in our multivariable analysis of patient-level risk factors for high dose variability are quite large. Therefore, the true magnitude of these effects is not precisely known. A final limitation is that this study evaluates patients with a target INR range of 2-3 and at least 1 month of experience with warfarin; our study results may not apply to patients who are new to warfarin or those with other target ranges.

\section{Conclusions}

In this study, we have derived and internally validated a new measure to identify patients at high risk for poor anticoagulation control in clinical practice, namely the coefficient of variation of weekly warfarin doses. This measure identifies patients at high risk for poor anticoagulation control and adverse events. Future studies should explore the use of this measure to identify patients for intervention before they have experienced an adverse event.

\section{List of Abbreviations}

VTE: Venous Thromboembolism; INR: International Normalized Ratio; TTR: Percent Time in Therapeutic Range; ACTION: The Anticoagulation Consortium to Improve Outcomes Nationally; CoV: Coefficient of Variation; OR: Odds Ratio.

\section{Acknowledgements}

AJR is supported by a career development award (CDA-2-08-017) from the United States Department of Veterans Affairs, Health Services Research and Development Service. The authors thank Elaine Hylek for generously providing access to the database.
Disclaimer

The opinions expressed in this manuscript do not necessarily represent the views or policies of the Department of Veterans Affairs.

\section{Author details}

${ }^{1}$ Department of Medicine, Boston University School of Medicine, Boston Medical Center, Boston, MA, USA. 'Biostatistics Section, Children's Hospital of Boston, Boston, MA, USA. ${ }^{3}$ Center for Health Quality, Outcomes, and Economic Research, Bedford VA Medical Center, Bedford, MA, USA.

\section{Authors' contributions}

LM helped conceive the study idea, performed chart reviews, and drafted the manuscript. ME helped conceive the study idea and performed chart reviews. AO performed statistical analyses and provided statistical supervision. LEH helped collect the data, performed statistical analyses, and managed the data. AJR helped conceive the study idea, performed chart reviews, performed statistical analyses, and provided study supervision. All authors participated in interpretation of interim results, made revisions to the manuscript for important intellectual content, and approved the final manuscript.

\section{Authors' Information}

LM and ME were third year internal medicine residents at Boston Medical Center at the time this study was performed. The results of this study were presented at the Society of General Internal Medicine's $33^{\text {rd }}$ annual

conference in Minneapolis, MN on April 30, 2010

\section{Competing interests}

Data collection for this study was sponsored by Bristol-Myers Squibb. The sponsor was not involved in the study design, study management, data collection, analysis, writing, revision, or decision to submit for publication. The authors do not have any other conflicts of interest to report.

Received: 12 May 2011 Accepted: 10 October 2011

Published: 10 October 2011

\section{References}

1. Ansell J, Hirsh J, Hylek E, Jacobson A, Crowther M, Palareti G: Pharmacology and Management of the Vitamin K Antagonists: American College of Chest Physicians Evidence-Based Clinical Practice Guidelines (8th Edition). Chest 2008, 133:160S-198S.

2. Salem DN, O'Gara PT, Madias C, Pauker SG: Valvular and structural heart disease: American College of Chest Physicians Evidence-Based Clinical Practice Guidelines (8th Edition). Chest 2008, 133.593S-629S.

3. Singer DE, Albers GW, Dalen JE, Fang MC, Go AS, Halperin JL, Lip GY, Manning WJ: Antithrombotic therapy in atrial fibrillation: American College of Chest Physicians Evidence-Based Clinical Practice Guidelines (8th Edition). Chest 2008, 133:546S-592S.

4. Kearon C, Kahn SR, Agnelli G, Goldhaber S, Raskob GE, Comerota AJ: Antithrombotic therapy for venous thromboembolic disease: American College of Chest Physicians Evidence-Based Clinical Practice Guidelines (8th Edition). Chest 2008, 133:454S-545S.

5. Wells PS, Holbrook AM, Crowther NR, Hirsh J: Interactions of warfarin with drugs and food. Ann Intern Med 1994, 121:676-683.

6. Holbrook AM, Pereira JA, Labiris R, McDonald H, Douketis JD, Crowther M, Wells PS: Systematic overview of warfarin and its drug and food interactions. Arch Intern Med 2005, 165:1095-1106.

7. Schulman S, Beyth RJ, Kearon C, Levine MN: Hemorrhagic complications of anticoagulant and thrombolytic treatment: American College of Chest Physicians Evidence-Based Clinical Practice Guidelines (8th Edition). Chest 2008, 133:257S-298S.

8. Linkins LA, Choi PT, Douketis JD: Clinical impact of bleeding in patients taking oral anticoagulant therapy for venous thromboembolism: a metaanalysis. Ann Intern Med 2003, 139:893-900.

9. Rose AJ, Ozonoff A, Grant RW, Henault LE, Hylek EM: The Epidemiology of Sub-Therapeutic Anticoagulation in the United States. Circ CardiovasC Qual Outcomes 2009, 2:591-597.

10. White HD, Gruber M, Feyzi J, Kaatz S, Tse H, Husted S, Albers GW: Comparison of outcomes among patients randomized to warfarin therapy according to anticoagulant control: results from SPORTIF III and V. Arch Intern Med 2007, 167:239-245. 
11. Connolly SJ, Pogue J, Eikelboom J, Flaker G, Commerford P, Franzosi MG, Healey JS, Yusuf S: Benefit of Oral Anticoagulant Over Antiplatelet Therapy in Atrial Fibrillation Depends on the Quality of International Normalized Ratio Control Achieved by Centers and Countries as Measured by Time in Therapeutic Range. Circulation 2008, 118:2029-2037.

12. Jones M, McEwan P, Morgan CL, Peters JR, Goodfellow J, Currie CJ: Evaluation of the pattern of treatment, level of anticoagulation control, and outcome of treatment with warfarin in patients with non-valvular atrial fibrillation: a record linkage study in a large British population. Heart 2005, 91:472-477.

13. Veeger NJ, Piersma-Wichers M, Tijssen JG, Hillege HL, van der Meer J: Individual time within target range in patients treated with vitamin $\mathrm{K}$ antagonists: main determinant of quality of anticoagulation and predictor of clinical outcome. A retrospective study of 2300 consecutive patients with venous thromboembolism. Br J Haematol 2005, 128:513-519.

14. van Walraven C, Oake N, Wells PS, Forster AJ: Burden of potentially avoidable anticoagulant-associated hemorrhagic and thromboembolic events in the elderly. Chest 2007, 131:1508-1515.

15. Rosendaal FR, Cannegieter SC, van der Meer FJ, Briet E: A method to determine the optimal intensity of oral anticoagulation therapy. Thromb Haemost 1993, 69:236-239.

16. Fihn SD, McDonell MB, Martin DC, Henikoff J, Vermes D, Kent D, White RH: Warfarin Optimized Outpatient Follow-up Study Group. Risk factors for complications of chronic anticoagulation. A multicenter study. Ann Intern Med 1993, 118:511-520.

17. Fihn SD, Callahan CM, Martin DC, McDonell MB, Henikoff JG, White RH: The risk for and severity of bleeding complications in elderly patients treated with warfarin. The National Consortium of Anticoagulation Clinics. Ann Intern Med 1996, 124:970-979.

18. Rose AJ, Hylek EM, Ozonoff A, Ash AS, Reisman Jl, Berlowitz DR: Patient Characteristics Associated with Oral Anticoagulation Control: Results of the Veterans Affairs Study to Improve Anticoagulation. J Thromb Haemost 2010, 8:2182-2191.

19. Rose AJ, Ozonoff A, Henault LE, Hylek EM: Warfarin for atrial fibrillation in community-based practice. J Thromb Haemost 2008, 6:1647-1654.

20. Garcia D, Regan S, Crowther M, Hughes RA, Hylek EM: Warfarin maintenance dosing patterns in clinical practice: implications for safer anticoagulation in the elderly population. Chest 2005, 127:2049-2056.

21. Garcia D, Regan S, Crowther M, Hylek EM: The risk of hemorrhage among patients with warfarin-associated coagulopathy. J Am Coll Cardiol 2006, 47:804-808.

22. Schulman S, Kearon C: Definition of major bleeding in clinical investigations of antihemostatic medicinal products in non-surgical patients. J Thromb Haemost 2005, 3:692-694.

23. van Walraven C, Austin PC, Oake N, Wells P, Mamdani M, Forster AJ: The effect of hospitalization on oral anticoagulation control: a populationbased study. Thromb Res 2007, 119:705-714.

24. Gebauer MG, Nyfort-Hansen K, Henschke PJ, Gallus AS: Warfarin and acetaminophen interaction. Pharmacotherapy 2003, 23:109-112.

25. Beckey NP, Stevens GR: The effect of acetaminophen on the international normalized ration in patients stabilized on warfarin therapy. Pharmacotherapy 2007, 27:675-683.

26. Hylek EM, Heiman H, Skates SJ, Sheehan MA, Singer DE: Acetaminophen and Other Risk Factors for Excessive Warfarin Anticoagulation. JAMA 1998, 279:657-662.

27. Launiainen T, Sajantila A, Rasanen I, Vuori E, Ojanpera I: Adverse interaction of warfarin and paracetamol: evidence from a post-mortem study. Eur $J$ Clin Pharmacol 2010, 66:97-103.

28. Gadisseur AP, Van Der Meer FJ, Rosendaal FR: Sustained intake of paracetamol (acetaminophen) during oral anticoagulant therapy with coumarins does not cause clinically important INR changes: a randomized double-blind clinical trial. J Thromb Haemost 2003, 1:714-717.

29. Fattinger K, Frisullo R, Masche U, Braunschweig S, Meier PJ, Roos M: No clinically relevant drug interaction between paracetamol and phenprocoumon based on a pharmacoepidemiological cohort study in medical inpatients. Eur J Clin Pharmacol 2002, 57:863-867.

30. van den Bemt PM, Geven LM, Kuitert NA, Risselada A, Brouwers JR: The potential interaction between oral anticoagulants and acetaminophen in everyday practice. Pharm World Sci 2002, 24:201-204.

31. Palareti G, Legnani C, Guazzaloca G, Lelia V, Cosmi B, Lunghi B, Marchetti G, Poli D, Pengo V, ad hoc Study Group of the Italian Federation of
Anticoagulation Clinics: Risks factors for highly unstable response to oral anticoagulation: a case-control study. Br J Haematol 2005, 129:72-78.

32. Witt DM, Delate T, Clark NP, Martell C, Tran T, Crowther MA, Garcia DA, Ageno W, Hylek EM: Warfarin Associated Research Projects and other EnDeavors (WARPED) Consortium. Outcomes and predictors of very stable INR control during chronic anticoagulation therapy. Blood 2009, 114:952-956.

33. Witt DM, Delate T, Clark NP, Martell C, Tran T, Crowther MA, Garcia DA, Ageno W, Hylek EM, WARPED Consortium: Twelve-month outcomes and predictors of very stable INR control in prevalent warfarin users. J Thromb Haemost 2010, 8:744-749.

doi:10.1186/1477-9560-9-14

Cite this article as: Marrast et al.: Using highly variable warfarin dosing to identify patients at risk for adverse events. Thrombosis Journal 2011 9:14.

\section{Submit your next manuscript to BioMed Central and take full advantage of:}

- Convenient online submission

- Thorough peer review

- No space constraints or color figure charges

- Immediate publication on acceptance

- Inclusion in PubMed, CAS, Scopus and Google Scholar

- Research which is freely available for redistribution

Submit your manuscript at www.biomedcentral.com/submit
Biomed Central 